\title{
Which Socio-Economic Factors Influence Patients' Choice to Opt for the ED or the GPC during Out-of-Hours: An Explorative Study in Flanders
}

\author{
Jens Detollenaere*, Evelyn Verlinde, Sara Willems, Jeftha Blezer \\ Department of General Practice and Primary Health Care, Ghent University, Ghent, Belgium \\ Email: "Jens.Detollenaere@UGent.be
}

Received 25 April 2014; revised 28 May 2014; accepted 4 June 2014

Copyright (C) 2014 by authors and Scientific Research Publishing Inc.

This work is licensed under the Creative Commons Attribution International License (CC BY). http://creativecommons.org/licenses/by/4.0/

(c) (i) Open Access

\begin{abstract}
Background: Overcrowding of emergency departments (ED) during out-of-hours health care is a common problem in many Western countries. An appealing alternative for ED's is the general practices cooperatives (GPC): regional networks of GP's during the out-of-hours. The aim of this study is to investigate the socio-economic determinants of patients' choice to opt for one of both health care providers. Methods: We gathered patient level data between May and December 2012 in Flanders (Belgium) from three emergency departments and three general practices cooperatives. Chi square analyses were used in order to study the bivariate relationship between opting for a health care facility (ED or GPC) and various socio-economic factors. To determine the independent association, a logistic regression analysis was conducted. Results: Self-referral to the ED is significantly associated with: being male, being younger, being less educated, having a (lower educated) partner and living in a rural area. Conclusion: The results of this study show that opting for the ED during the out-of-hours is, in general, related to a lower socio-economic status. Therefore the government should focus on patients with a lower socio-economic status when disseminating information on the organisation of health care with an emphasis on the accessibility of the primary health care during out-of-hours. To meet the needs for health care during these out-ofhours, a possible solution could be an integrated facility of GPC and ED with one access to medical care for all patients.
\end{abstract}

\section{Keywords}

Emergency Department, General Practices Cooperatives, Out-of-Hours Health Care, Primary Health Care and Health Care Access

\footnotetext{
${ }^{*}$ Corresponding author.
}

How to cite this paper: Detollenaere, J., Verlinde, E., Willems, S. and Blezer, J. (2014) Which Socio-Economic Factors Influence Patients' Choice to Opt for the ED or the GPC during Out-of-Hours: An Explorative Study in Flanders. Health, 6, 13611367. http://dx.doi.org/10.4236/health.2014.612167 


\section{Introduction}

Recently, there is a growing interest in the use of emergency department (ED) health facilities [1] [2]. Excessive use of ED health care imposes considerable costs on society. Firstly, the marginal costs of care provided in an ED outpatient visit are higher than those in other settings [3] [4]. Secondly, non-urgent use of the ED can result in overcrowding, which is a common problem in many Western countries [5].

In order to advise policy makers on how to change health seeking behaviour, researchers have been relating health care usage to socio-economic status and thereby indicating target groups for awareness campaigns. Literature shows that ED usage frequencies are positively associated with a lower socio-economic status; being young [2] [6] [7], male [1] [6]-[9], of foreign nationality [9]-[12], living in urban areas [1] [8] [10] and having no health insurance or being publicly insured [3] [13]-[16]. The identification of ED usage relative to out-ofhours primary care usage determinants, however, has not been addressed extensively in the literature. To the best of our knowledge, scarce literature provides evidence for socio-economic factors driving the usage of one both health care services. These studies show that patients presenting at the GPC are relatively more often female, older and residing in rural areas [8].

In this study we provide evidence for Belgium. The Belgian health care system achieves almost universal public coverage of the population for the majority of health care services with direct access to any general practitioner and specialist at any time for any problem [17]. In the Belgian fee-for-service system, patients pay about $30 \%$ co-payment for primary health care and $40 \%$ for specialist care, with reduced co-payment rates (8\%) for lower socio-economic groups [17]. Approximately 99\% of the Belgian population is covered by a compulsory health insurance [18]. Furthermore, there is a legal obligation to provide a $24 \mathrm{~h} / 24 \mathrm{~h}$ coverage of medical care [4] [9]. During the out-of-hours, until recently patients' only alternative for ED health care was to opt for a GP on call. This resulted in a heavy workload for these physicians. Following the Netherlands [7] [19], the organisation of out-of-hours health care in Belgium has developed a new facility of regional networks to meet this workload during the out-of-hours, named the GPC [17]. Nowadays, approximately $10 \%$ of the Flemish population in Belgium is covered by a GPC [20]. In this study we aim to investigate the impact of socio-economic determinants on the use of the ED respectively, the GPC during out-of-hours in Flanders, Belgium.

\section{Methods}

\subsection{Setting}

Data was gathered in three ED’s in Flanders, Belgium: two rural areas (Deinze, Tielt), one urban area (Ghent) and from three GPC's in Ghent.

\subsection{Participants and Sample}

Data was collected during the after-hours in two periods. First, from May to August 2012 data was collected at the Sint-Vincentiushospital Deinze, the Ghent University Hospital, and three GPC's in Ghent. Second, from October to December 2012, data was collected in the Sint-Andrieshospital Tielt. The interviewers asked adult patients ( $\geq 18$ years) presenting at the aforementioned health care departments to participate in the study after their treatment. Exclusion criteria for the ED were, besides age under 18 years, referral by GP and entering the hospital by ambulance or mobile urgency group (MUG). People who could not understand Dutch, French, English, Russian or Turkish were also not included. All participants gave written consent. This study was approved by the Ethics Committee of Ghent University Hospital (reference number 2012/555).

\subsection{Data Collection}

Data were collected by means of a face-to-face survey. The questionnaire was developed, based on the international literature and expert opinion and was translated in French, English, Russian and Turkish in order to reach a wide variety of patients. In view of our research goal, questions were focussed on socio-economic and demographic characteristics of the patients.

\subsection{Data Analysis}

The collected data were analysed using SPSS (version 21.0.0, IBM). First, by using descriptive statistics and 
chi-squared tests the main determinants for choosing the GPC or the ED were identified. Second, multiple logistic regression was used to assess the relative contribution of these determinants of choosing for the GPC respectively for the ED. In order to answer our research question on the one hand we included specific demographic determinants like gender, age, area of residence and on the other hand we added socio-economic factors like educational level of the respondent, occupation, presence of a partner, educational level of the partner, additional health insurance and ethnicity. The adoption of the education level of the partner is new to the literature. We believe that this variable adds additional information on the social capital of the patient and complements the education level and the employment status of the patient in capturing the socio-economic status of the household. Moreover, the decision to opt for a particular health care provider is probably influenced by the patient's partner. In addition we also controlled for health status which was measured by the patient's perceived general health. All variables were operationalised as categorical variables. Note that, as approximately $99 \%$ of the Belgian population is covered by a compulsory health insurance, the variable "additional health insurance" in our analyses indicates individuals who buy additional insurance (giving them e.g. the right to get a private room in case of hospitalisation). The enterwise model was used to select the final model. We checked for a selection bias and multicollinearity, the level of significance was tested by Bald test and $\mathrm{p}<0.05$ was set as being the level of statistical significance.

\section{Results}

A total of 294 patients participated in the study, including $48.1 \%$ men and $51.9 \%$ women. Other characteristics of the population are that $18.3 \%$ of the respondents are low educated, $39.0 \%$ are middle educated and $42.8 \%$ are high educated. $66.9 \%$ of the respondents are employed and $33.1 \%$ have no paid work or are retired. Table 1 presents the univariable comparison between ED and GPC respondents. The proportion of men in ED health care is significantly higher than in GPC health care $(p=0.006)$. ED respondents have a lower educational level ( $p<0.001$ ) than patients visiting the GPC. Approximately $70 \%$ of the ED participants report to be in good or very good health, compared to $84 \%$ at the GPC $(p=0.004)$. Moreover, ED respondents are less covered by an additional health insurance $(\mathrm{p}=0.026)$ than those visiting the GPC. More ED respondents have a partner $(\mathrm{p}=$ 0.002), compared to the GPC respondents. Concerning the educational level of the partner of the respondent, we find a higher proportion of individuals with higher educated partners at the GPC while at the ED there are more respondents without a partner or with no higher educated partner $(<0.001)$. Last, ED users live less in the centre of a city and in urban areas $(\mathrm{p}<0.001)$ than GPC users. We observe no significant association between age, occupation, ethnicity and the usage of one of both health care services.

To determine the independent impact of socio-economic determinants on the choice to opt for the ED or GPC, a multiple logistic regression model on the usage of ED or GPC was built, adjusting for general health. Table 2 shows the results of this regression. Our model explained $55.4 \%$ of the variance in the choice to opt for the ED instead of for the GPC. Firstly, we see that patients who reside in urban (OR = 5.966, 95\% CI: 2.246 - 15.846) and rural (OR = 28.421, 95\% CI: 9.973 - 80.995) areas and have a partner (OR = 3.634, 95\% CI: 1.360 - 9.712) show a significantly higher likelihood to choose for the ED instead of the GPC. Secondly, respondents with a higher age (OR $=0.376,95 \%$ CI: 0.148 - 0.954), a higher education level ( $\mathrm{OR}=0.159,95 \%$ CI: 0.044 - 0.572$)$ and a higher educated partner $(\mathrm{OR}=0.293,95 \%$ CI: 0.112 - 0.767) show a significantly higher likelihood to opt for the GPC than for the ED facility.

\section{Discussion}

The aim of this study was to determine the socio-economic determinants of the use of out-of-hours health care in Flanders (Belgium). We focus on socio-economic determinants in order to advice policy makers on how to change health seeking behaviour by indicating target groups for awareness campaigns on the accessibility of primary health care during the out-of-hours. The results of this study are largely consistent with the consulted literature. Patients who opt for the ED (instead of the GPC) seem to be younger, are more often of the male gender, have a lower educational level, are more likely to have a partner but less likely to have a higher educated partner and are less likely to live in the city centre or in urban areas. Also the fact that we find no significant role for occupation is in line with the literature [2].

As a first part of the discussion of our study, we provide the reader with more intuition on our research results for some of our adopted socio-economic variables. First, the education level of the patient, which is positively 
Table 1. ED versus GPC usage: descriptive and univariable results.

\begin{tabular}{|c|c|c|c|}
\hline & ED n (\%) & GPC n (\%) & $\mathrm{p}^{*}$ \\
\hline $\begin{array}{l}\text { Gender } \\
\text { Male } \\
\text { Female }\end{array}$ & $\begin{array}{c}193 \\
104(53.9) \\
89(46.1)\end{array}$ & $\begin{array}{c}101 \\
37(36.6) \\
63(62.4)\end{array}$ & 0.006 \\
\hline $\begin{array}{c}\text { Age } \\
18-35 \\
36-55 \\
56+\end{array}$ & $\begin{array}{c}192 \\
92(47.9) \\
65(33.9) \\
35(18.2)\end{array}$ & $\begin{array}{c}99 \\
48(48.5) \\
28(28.3) \\
23(23.2)\end{array}$ & 0.482 \\
\hline $\begin{array}{l}\text { General health } \\
\text { Very poor-poor } \\
\text { Reasonable } \\
\text { Good-very good }\end{array}$ & $\begin{array}{c}190 \\
20(10.5) \\
37(19.5) \\
133(70.0)\end{array}$ & $\begin{array}{c}101 \\
1(1.0) \\
15(14.9) \\
85(84.2)\end{array}$ & 0.004 \\
\hline $\begin{array}{l}\text { Area residence } \\
\text { City center } \\
\text { Urban } \\
\text { Rural }\end{array}$ & $\begin{array}{c}184 \\
20(10.9) \\
62(33.7) \\
102(55.4)\end{array}$ & $\begin{array}{c}91 \\
52(57.1) \\
26(28.6) \\
13(14.3)\end{array}$ & $<0.001$ \\
\hline $\begin{array}{c}\text { Educational level } \\
\text { Low } \\
\text { Medium } \\
\text { High }\end{array}$ & $\begin{array}{c}190 \\
46(24.2) \\
87(45.8) \\
57(30.0)\end{array}$ & $\begin{array}{c}100 \\
7(7.0) \\
26(26.0) \\
67(67.0)\end{array}$ & $<0.001$ \\
\hline $\begin{array}{l}\text { Occupation } \\
\text { No permanent employment or temporary interrupted } \\
\text { Permanent paid employment }\end{array}$ & $\begin{array}{c}188 \\
63(33.5) \\
125(66.5)\end{array}$ & $\begin{array}{c}99 \\
32(32.3)\end{array}$ & 0.839 \\
\hline $\begin{array}{l}\text { Partner } \\
\text { No } \\
\text { Yes }\end{array}$ & $\begin{array}{c}190 \\
36(18.9) \\
139(73.2)\end{array}$ & $\begin{array}{c}101 \\
34(33.7) \\
66(65.3)\end{array}$ & 0.002 \\
\hline $\begin{array}{l}\text { Educational level partner } \\
\text { No partner or no higher educated partner } \\
\text { Higher educated partner }\end{array}$ & $\begin{array}{c}167 \\
124(74.3) \\
43(25.7)\end{array}$ & $\begin{array}{c}98 \\
52(53.1) \\
46(46.9)\end{array}$ & $<0.001$ \\
\hline $\begin{array}{c}\text { Additional health insurance } \\
\text { No } \\
\text { Yes }\end{array}$ & $\begin{array}{c}191 \\
40(20.9) \\
150(78.5)\end{array}$ & $\begin{array}{c}100 \\
9(9.0) \\
91(91.0)\end{array}$ & 0.026 \\
\hline $\begin{array}{c}\text { Ethnicity } \\
\text { Belgium } \\
\text { Outside Belgium }\end{array}$ & $\begin{array}{c}192 \\
171(89.1) \\
21(10.9)\end{array}$ & $\begin{array}{c}101 \\
95(94.1) \\
6(5.9)\end{array}$ & 0.160 \\
\hline
\end{tabular}

*All significant results are indicated in bold.

related to the choice to opt for the GPC, suggests what his lifestyle may be and thereby gives an indication of the physical and social safety net of the person and the behavioural patterns related to the use of health care facilities [5]. As a consultation at a GPC must be paid immediately while a visit to the ED should not be paid right away, liquidity constraints might push patients with a lower social status into ED usage (when asked for the major reasons to opt for the ED, five respondents point spontaneously to financial motives). In addition, Philips, Rotthier, Meyvis \& Remmen (2011) [21] report that patients who have no diploma, a diploma of special education or lower secondary education postpone more primary health care compared with individuals holding a higher degree. As a result of this postponement, health problems might get worse so that ED health care become the only appropriate option. This result might also mirror a knowledge issue: the lower educated are less informed about more recent health care provisions. In our full sample, $21.7 \%$ of the low educated respondents are not aware of GPC health care facilities compared with $10.0 \%$ among the high educated. Second, the same reasoning is appropriate for the negative effect of high educated partners on ED usage. Clearly, ED usage is correlated with lower socio-economic characteristics. Third, our finding of no significant role for occupation might be explained by the fact that this variable is correlated with educational level: people with a higher education are more likely to get better jobs [22]. Moreover, this finding is in line with the aforementioned knowledge issue driving the health care provider choice. Fourth, in contrast to the international literature, for ethnicity and health 
Table 2. Logistic regression model for choosing the ED.

\begin{tabular}{|c|c|c|c|c|c|c|}
\hline & Estimate & SE & Wald & $\mathrm{p}^{*}$ & Odds ratio & $95 \%$ CI \\
\hline \multicolumn{7}{|l|}{ Gender } \\
\hline Female & -1.072 & 0.406 & 6.974 & 0.008 & 0.342 & $0.155-0.759$ \\
\hline $\begin{array}{c}\text { Age } \\
18-35\end{array}$ & \multicolumn{5}{|c|}{ Age } & \\
\hline $36-55$ & -0.979 & 0.475 & 4.238 & 0.040 & 0.376 & $0.148-0.954$ \\
\hline $56+$ & -0.984 & 0.530 & 3.446 & 0.063 & 0.374 & $0.132-1.056$ \\
\hline \multicolumn{7}{|l|}{ General health } \\
\hline Very poor—poor & & & 3.113 & 0.211 & & \\
\hline Reasonable & -1.281 & 1.205 & 1.130 & 0.288 & 0.278 & $0.026-2.948$ \\
\hline Good—very good & -1.762 & 1.140 & 2.387 & 0.122 & 0.172 & $0.018-1.605$ \\
\hline \multicolumn{7}{|l|}{ Area residence } \\
\hline City centre & & & 39.321 & $<0.001$ & & \\
\hline Urban & 1.786 & 0.498 & 12.840 & $<0.001$ & 5.966 & $2.246-15.846$ \\
\hline Rural & 3.347 & 0.534 & 39.242 & $<0.001$ & 28.421 & $9.973-80.995$ \\
\hline \multicolumn{7}{|l|}{ Educational level } \\
\hline Low & & & 8.451 & 0.015 & & \\
\hline Medium & -1.117 & 0.649 & 2.964 & 0.085 & 0.327 & $0.092-1.167$ \\
\hline High & -1.837 & 0.652 & 7.933 & 0.005 & 0.159 & $0.044-0.572$ \\
\hline \multicolumn{7}{|l|}{ Occupation } \\
\hline No permanent employment & 0.448 & 0.466 & 0.926 & 0.336 & 1.566 & $0.628-3.902$ \\
\hline \multicolumn{7}{|l|}{ Partner } \\
\hline Yes & 1.290 & 0.502 & 6.617 & 0.010 & 3.634 & $1.360-9.712$ \\
\hline $\begin{array}{l}\text { Educational level partner } \\
\text { No partner or no higher educated partner }\end{array}$ & -1.227 & 0.491 & 6.259 & 0.012 & 0.293 & $0.112-0.767$ \\
\hline \multicolumn{7}{|l|}{ Additional health insurance } \\
\hline $\begin{array}{l}\text { No } \\
\text { Yes }\end{array}$ & -0.864 & 0.628 & 1.889 & 0.169 & 0.422 & $0.123-1.445$ \\
\hline
\end{tabular}

*All significant results are indicated in bold. Nagelkerke $\mathrm{R}^{2}: 0.554$.

insurance we get no significant effects while some former studies found evidence for a determining role. The finding of no significant role for ethnicity, on the one hand, might be related to the small fraction of respondents with a foreign nationality (resulting in high standard errors). Our insignificant result for health insurance, on the other hand, might be driven by the fact that our variable "additional health insurance" captures additional health insurance next to the compulsory insurance which is not the case for other studies (as the system of compulsory insurance is unique for Belgium). This finding indicates that stimulating additional insurances might not be a fruitful policy option in order to tackle inappropriate use of ED facilities.

In addition to our adoption of the education level of the partner and occupation as socio-economic determinants, the merits of the present research lie in the fact that, to the best of our knowledge, only one study in the scarce literature, Giesen et al. (2006), for the Netherlands, previously examined the socio-economic factors driving the usage of the GPC and ED. In this study, the patient records were retrospectively analysed in one region, while we conducted face-to-face interviews using a structured questionnaire in different regions. Moreover, our questionnaire was conducted in five different languages, which gave us an opportunity to interview a wider variety of patients. We confirm the results of Giesen et al. (2006) in finding higher GPC likelihoods for women and older respondents. In contrast, where they find more rural patients opting for the GPC, we observe the opposite in our dataset.

\section{Limitations and Recommendations}

This study has also some limitations. First of all our questionnaire was presented to ED patients in both urban 
and rural hospitals but only to GPC patients in one urban area. This is due to the fact that there are no GPC's in the studied rural areas (Deinze and Tielt), which limits the generalisability of the results to some extent. A second limitation lies in the relatively small sample size of respondents, which affected the precision of the presented results.

The organisation of out-of-hours primary health care is in need for change. Inappropriate use of ED is linked to the "urgency" and "emergency" of a medical problem. However, literature shows that patients and physicians have a different perception on the concept of "emergency" [6]. First of all, patients are not schooled to distinguish true emergencies from non-urgent problems, making it difficult for them to assess which health care facility is most suitable for their complaint. It has been shown that patients often overestimate the severity of their condition, and therefore, unnecessarily choose the ED over another health care facility. A second problem occurs when measuring inappropriate use. When studying health care use, researchers judge the complaints retrospectively to determine appropriateness. This is something that patients cannot do; they cannot judge on beforehand whether or not their visit is going to be justifiable [1]. And finally, where physicians often consider the issue to be strictly medical, one must take into account that patients and physicians often don't have the same agenda and that patients contact health care facilities for varying, sometimes non-medical, reasons [2]. In this respect integrating ED and GPC in one health care unit could be fruitful [23]. Patients suffering from a health problem during the out-of-hours, could present their problem at this organization. In such a system patients do not have to choose between one or another; they are always at the right place. Further research could be conducted concerning the (cost-) effectiveness of this new form of out-of-hours primary health care. In addition, one could investigate whether this integrated health care facility would have an impact on the caseload of ED's. Awaiting the results of this potential future research, governments should focus on patients with a lower socioeconomic status when disseminating information on the organisation of health care given our findings that opting for the ED during the out-of-hours is, in general, related to lower socio-economic status and that the lower educated are less informed about more recent health care provisions.

\section{Acknowledgements}

The authors would like to express their gratitude to the Ghent University Hospital, the Sint-Vincentiushospital in Deinze, the Sint-Andrieshospital in Tielt and the three GPC's in Ghent for their permission to conduct the study and to Annelies Lippens who composed the questionnaire we used in this research.

\section{Conflicts of Interest}

The authors declare that they have no competing interests.

\section{Funding}

None.

\section{References}

[1] Moll van Charante, E.P., Van Riet, G. and Bindels, P.J.E. (2007) Self-Refferrals to the A\&E Department during Outof-Hours: Patients' Motives and Characteristics. Patient Education and Counseling, 70, 256-265.

[2] Afilalo, J., Marinovich, A., Afilalo, M., Colacone, A., Léger, R., Unger, B. and Giguère, C. (2004) Nonurgent Emergency Department Patient Characteristics and Barriers to Primary Care. Academic Emergency Medicine, 11, $1302-1310$. http://dx.doi.org/10.1111/j.1553-2712.2004.tb01918.x

[3] Brim, C. (2008) A Descriptive Analysis of the Non-Urgent Use of Emergency Departments. Nurse Researcher, 15, 72-88. http://dx.doi.org/10.7748/nr2008.04.15.3.72.c6458

[4] Bamezai, A. Melnick, G. and Nawathe, A. (2005) The Cost of an Emergency Department Visit and Its Relationship to Emergency Department Volume. Annals of Emergency Medicine, 45, 483-490. http://dx.doi.org/10.1016/j.annemergmed.2004.08.029

[5] Gourbin, C. et al. (2005) KCE rapport, Evaluatie van forfaitaire persoonlijke bijdrage op het gebruik van spoedgevallendienst. KCE Reports, 19A.

[6] Philips, H. (2010) Out-of-Hours Primary Care in Belgium. Dissertation for the Degree of Doctor in Medical Sciences, Faculty Medicine. University of Antwerp, Antwerp. 
[7] Van Uden, C.J.T., Winkens, R.A.G., Wesseling, G., Fiolet, H.F.B.M., van Schayck, O.C.P. and Crebolder, H.F.J.M. (2005) The Impact of a Primary Care Physician Cooperative on the Caseload of an Emergency Department: The Maastricht Integrated Out-of-Hours Service. Journal of General Internal Medicine, 20, 612-617. http://dx.doi.org/10.1111/j.1525-1497.2005.0091.x

[8] Giesen, P., Franssen, E., Mokkink, H., van den Bosch, W., van Vugt, A. and Grol, R. (2006) Patients Either Contacting a General Practice Cooperative or Accident and Emergency Department out of Hours: A Comparison. Emergency Medicine Journal, 23, 731-734. http://dx.doi.org/10.1136/emj.2005.032359

[9] Wens, J., Mortelmans, L.J.M., Verhoeven, V., Philips, H., Remmen, R. and van Royen, P. (2005) Use of Emergency Departments by Primary Care Patients. European Journal of General Practice, 11, 78-80. http://dx.doi.org/10.3109/13814780509178243

[10] Padgett, D.K. and Brodsky, B. (1992) Psychosocial Factors Influencing Non-Urgent Use of the Emergency Room: A Review of the Literature and Recommendations for Research and Improved Service Delivery. Social Science \& Medicine, 35, 1189-1997. http://dx.doi.org/10.1016/0277-9536(92)90231-E

[11] Philips, H., Remmen, R., De Paepe, P., Buylaert, W. and Van Royen, P. (2010) Out of Hours Care: A Profile Analysis of Patients Attending the Emergency Department and the General Practitioner on Call. BMC Family Practice, 11, 88. http://dx.doi.org/10.1186/1471-2296-11-88

[12] Liu, T., Sayre, M.R. and Carleton, S.T. (1999) Emergency Medical Care: Types, Trends, and Factors Related to Nonurgent Visits. Academic Emergency Medicine, 6, 1147-1152. http://dx.doi.org/10.1111/j.1553-2712.1999.tb00118.x

[13] Weber, E.J., Showstack, J.A., Hunt, K.A., Colby, D.C. and Callaham, M.L. (2005) Does Lack of a Usual Source of Care or Health Insurance Increase the Likelihood of an Emergency Department Visit? Results of a National Population-Based Study. Annals of Emergency Medicine, 45, 4-12. http://dx.doi.org/10.1016/j.annemergmed.2004.06.023

[14] Zuckerman, S. and Shen, Y.C. (2004) Characteristics of Occasional and Frequent Emergency Department Users: Do Insurance Coverage and Access to Care Matter? Medical Care, 42, 176-182. http://dx.doi.org/10.1097/01.mlr.0000108747.51198.41

[15] Fidela, S.J., Li, H., Henneman, P.L., Smithline, H.A., Santoro, J.S., Provost, D. and Maynard, A.M. (2005) A Descriptive Study of Heavy Emergency Department Users at an Academic Emergency Department Reveals Heavy ED Users Have Better Access to Care Than Average Users. Journal of Emergency Nursing, 31, 139-144. http://dx.doi.org/10.1016/j.jen.2005.02.008

[16] Weber, E.J., Showstack, J.A., Hunt, K.A., Colby, D.C., Grimes, B., Bacchetti, P. and Callaham, M.L. (2008) Are the Uninsured Responsible for the Increase in Emergency Department Visits in the United States? Annals of Emergency Medicine, 52, 108-115. http://dx.doi.org/10.1016/j.annemergmed.2008.01.327

[17] Den Boer-Wolters, D., Knol, M.J., Smulder, K. and De Wit, N.J. (2010) Frequent Attendance of Primary Care Out-ofHours Services in the Netherlands: Characteristics of Patients and Presented Morbidity. Family Practice, 27, 129-134. http://dx.doi.org/10.1093/fampra/cmp103

[18] Gerkens, S., et al. (2010) Het Belgisch Gezondheidssysteem in 2010. KCE Reports.

[19] Moll van Charante, E.P., Van Steenwijk-Opdam, P.C.E. and Bindels, P.J.E. (2007) Out-of-Hours Demand for GP Care and Emergency Services: Patients' Choices and Referrals by General Practitioners and Ambulance Services. BMC Family Practice, 8, 46.

[20] Remmen, R., et al. (2007) Huisartsenwachtposten in Vlaanderen: Wat zijn de randvoorwaarden? Huisarts $\mathrm{Nu}$, 36, 397-401.

[21] Philips, H., Rotthier, P., Meyvis, L. and Remmen, R. (2011) Gebruik en toegankelijkheid van de eerstelijnsgezondheidszorg. Hoe bepalend is de sociaal-economische situatie in Antwerpen? Huisarts Nu, 40, 327-362.

[22] Andersen, R. and Newman, J.F. (2005) Societal and Individual Determinants of Medical Care Utilisation in the United States. The Milbank Quarterly, 83, 1-28. http://dx.doi.org/10.1111/j.1468-0009.2005.00428.x

[23] Giesen, P., Franssen, E., Mokkink, H., van den Bosch, W., van Vugt, A. and Grol, R. (2007) Medische zorg buiten kantooruren: De huisartsenpost of de spoedeisende eerste hulp? Huisarts en Wetenschap, 50, 338-343. http://dx.doi.org/10.1007/BF03085163 